\title{
MiR-155 contribute to airway inflammation in COPD by regulating autophagy via targeting TLR4/NF-KB
}

\author{
Mingliang WANG ${ }^{1}$, Wendong WANG ${ }^{1}$, Jiashun WANG ${ }^{1}$, Jun $\mathrm{ZHANG}^{1 *}$ (D)
}

\begin{abstract}
To evaluate the expression of miR-155 and autophagy in COPD and the related mechanism. Alveolar macrophages were extracted from COPD patients. COPD dynamic mouse model was established. Mouse alveolar macrophages were also isolated and cultured. Rat alveolar macrophage cell line NR8383 was introduced. The expression of TLR4 and NF-kB in NR8383 cells with CSE treatment was also evaluated. miR-155 was upregulated in alveolar macrophages from bronchoalveolar lavage fluid of COPD patients, COPD dynamic mouse model and CSE treated NR8383 cell line $(\mathrm{p}<0.05)$. Overexpression of miR-155 led to dysregulation of cell autophagy and was closely. miR-155 promoted cell autophagy by directly targeting TLR4/NF- $\mathrm{kB}$ pathway in NR8383 cell line. Our study revealed a novel inflammatory role of miR-155 in COPD and the related mechanisms. We provide a new perspective to understand the pathogenesis of COPD, and miR-155 might be useful as potential target for the treatment of COPD.
\end{abstract}

Keywords: autophagy; miR-155; airway inflammation; COPD.

Practical application: We provide a new perspective to understand the pathogenesis of Chronic obstructive pulmonary disease, and miR-155 might be useful as potential target for the treatment of Chronic obstructive pulmonary disease.

\section{Introduction}

Chronic obstructive pulmonary disease (COPD) is characterized by persistent airflow limitation and air-way remodeling, which is one of the major cause of morbidity and mortality worldwide and predict to be the third leading cause of death by 2030 (Postma et al., 2015; Kim et al., 2017). Smoking or cigarette smoke extract exposure can cause local infiltration of inflammatory cells such as macrophages, lymphocytes and neutrophils, eventually leading to lung damage and the stenosis of small airway, which is considered as the predominant factor and attributed to approximately $80-90 \%$ of the COPD cases (Tuder \& Petrache, 2012). However, only 10-15\% of smokers develop COPD, implying other factors, such as genetic factors, may increase the risk in certain individuals (Mayer \& Newman, 2001). Alveolar macrophages were considered as the first line of the innate immune defense against cigarette smoke attack through the secretion of various pro-inflammatory mediators and production of airway mucus, which are directly related to the occurrence and progression of airflow limitation and airway remodeling, and then leads to COPD (Thepen et al., 1994; Murugan \& Peck, 2009).

Autophagy is the basic cellular process helping to maintain the homeostatic balance among the synthesis, degradation and recycling of cellular proteins and organelles. Although autophagy occurs at basal levels in all cells to maintain cellular homeostasis, it is also initiated by various cellular stresses or environmental conditions, such as oxidants, inflammation, hypoxia, or inhaled xenobiotics (Ryter \& Choi, 2010; Cheng et al., 2009; Racanelli et al., 2018). The complete autophagy process includes autophagosome production, autophagosome binding degradation substrate, autophagosome fuses with a lysosome and autophagic substrate degradation (Parzych \& Klionsky, 2014). Beclin1 is involved in the initial stage of autophagy and plays a role in initiating autophagy (Ha \& Kim, 2016). LC3-II is a marker for autophagosome formation (Heckmann et al., 2017). The autophagy substrate $\mathrm{p} 62$ recognizes the ubiquitinated degradation substrate, which are bound and degraded by autophagosomes, after that, the protein level is down regulated (Katsuragi et al., 2015). Recent studies have shown a marked increase in the expression of markers of autophagy in lungs of patients with COPD and in mice lung cells exposed to CS (Zeng et al., 2018; Sukkar \& Harris, 2017; Wu et al., 2020), but the mechanism is not completely understood.

MicroRNAs (miRNAs or miRs) are a class of small non-coding RNA molecules (19-35 nucleotides in length) which modulate the levels of specific genes and proteins (Li \& Rana, 2014). MiR-155 is a typical multifunctional miRNA located in the third exon of the B-cell Integration Cluster gene on human chromosome 21 is involved in the development of various diseases including pulmonary inflammatory diseases (Faraoni et al., 2009). Using a mouse model of lung injury induced by influenza infection, 
it was found that lung inflammation was significantly inhibited in miR-155 knockout mice (Pociask et al., 2017). In cell model, overexpression of miR-155 significantly aggravated LPS-induced lung epithelial cell damage and inflammatory factor production, while inhibition of miR-155 was resistant to LPS-induced lung epithelial cell injury and inflammatory factor production (Zech et al., 2015). However, the role and molecular mechanisms underlying the regulation of miR-155 on the inflammation and autophagy of CS-induced COPD are still unknown. Therefore, in this study, we evaluated the expression of miR-155 and autophagy in COPD and the related mechanism.

\section{Materials and methods}

\subsection{Patients}

All patients were required to meet the following criteria, above 45 years old; no history of upper respiratory tract infection in the past 4 weeks; no history of glucocorticoid use in the past 4 weeks; no history of tuberculosis, pleural disease; no diabetes, hypertension, malignant tumors or autoimmune-related diseases; cooperate with the investigation; cooperate with the completion of pulmonary function tests. The study was approved byour hospital. All patients agreed to participate in the study and signed the informed consent form.

All patients were divided into five groups: non-smokers without $\operatorname{COPD}(n=20)$; smokers without $\operatorname{COPD}(n=20)$, smokers with mild COPD (FEV1/FVC $>70 \%$, FEV1 $\geq 80 \%$, with chronic symptoms, $\mathrm{n}=20$ ), smokers with moderate COPD (FEV1/FVC $<70 \%, 30 \% \leq \mathrm{FEV} 1 \leq 80 \%$, with chronic symptoms, $\mathrm{n}=20$ ), smokers with severe COPD (FEV1/FVC $<70 \%$, FEV $1<30 \%$, respiratory failure or right heart failure, $n=20$ ). The diagnosis of COPD was based on the criteria of the Global Initiative for Chronic Obstruct Lung Disease (COLD).

\subsection{Extraction of alveolar macrophages from COPD patients}

Flexible bronchoscopies (Olympus BF-1T160bronchoscope, Olympus Corporation, Tokyo, Japan) were performed under local anesthesia (2\% lidocaine) after premedication with inhaled salbutamol $(400 \mu \mathrm{g})$, intramuscular atropine $(0.5 \mathrm{mg})$ and oral midazolam $(7.5 \mathrm{mg})$. Supplemental oxygen was applied during the entire procedure and blood oxygen saturation was monitored with a pulse oximeter (Pulsox DP-8, Konica Minolta Inc., Tokyo, Japan) (Proboszcz et al., 2017). Following macroscopic inspection of the bronchial tree, BAL was performed by wedging the bronchoscope in the bronchi of the middle lobe or the lingula and administering $4 \times 50 \mathrm{ml}$ sterile $\mathrm{NaCl}$ warmed to $37^{\circ} \mathrm{C}$. Gentle suction was applied to transfer the BALF into sterile containers. After a double nylon gauze filtration, lavage fluid was centrifuged for $10 \mathrm{~min}$ at $500 \mathrm{rpm}$ at $4{ }^{\circ} \mathrm{C}$.

The extracted BALF was centrifuged in a centrifuge tube $\left(1000 \mathrm{r} / \mathrm{min}\right.$, centrifuged for $10 \mathrm{~min}, 4^{\circ} \mathrm{C}$ ), and the supernatant was discarded after centrifugation. Approximate $0.5 \mathrm{ml}$ of the cell suspension was left at the bottom of the tube, and the cell components precipitated by centrifugation were washed twice under the same conditions every $5 \mathrm{~min}$. After discarding the supernatant and suspending the cells, $10 \mu \mathrm{l}$ cells were taken to the counting plate. A small amount of cell suspension smear was taken. After drying, cells were stained with wright and counted 200 cells under $40 \times$ optical microscope for classification. The remaining cells are attached. Adding about $5 \mathrm{ml}$ of $10 \%$ calf serum RPMI 1640 medium to the culture flask, the cell suspension was added, and incubated for $2 \mathrm{~h}\left(37^{\circ} \mathrm{C}, 5 \% \mathrm{CO}_{2}\right)$ for adherence treatment, adherent alveolar sleep. Then cells were scraped, suspended in PBS, and the cell suspension was pipetted out to an EP tube. A small amount of tube bottom cell suspension was pipetted to a counting plate, stained with trypan blue, and the cell viability was evaluated.

\subsection{COPD dynamic mouse model}

48 wild type C57BL/6J mice were divided into non-smoking group, smoking 2 weeks group, smoking 4 weeks group, smoking 6 weeks group, smoking 8 weeks group, smoking 15 weeks + tracheal infusion $200 \mu \mathrm{g} / \mathrm{kg}$ LPS group (8 mice each).

The smoking group was placed in the homemade smoke exposure box, which was $80 \mathrm{~cm} \times 60 \mathrm{~cm} \times 30 \mathrm{~cm}$, one side opened the mouthpiece, the other side opened the small hole to place the cigarette, and the top part had a $5 \mathrm{~cm} \times 30 \mathrm{~cm}$ observation window. Cigarette smoke exposure was given 16 times a day. The smoke concentration in the cabinet is controlled at about $7 \%$, each exposure time lasts $40 \mathrm{~min}$, each passive smoking interval is $4 \mathrm{~h}$. The wall of the box is used once to prevent the animals from getting together and causing uneven smoking. Non-smoking subgroup mice were not exposed to cigarette smoke.

\subsection{Fresh isolation and culture of mouse alveolar macrophages}

Blood were collected from the ocular artery directly from the mice after eyeball removal. After aseptic treatment, the trachea is exposed, and the disinfected tissue is cut on the trachea to make a mouth (not to be cut), the trachea was inserted from the incision with a sterile soft tube attached to a syringe, and the wire was fixed. The PBS solution preheated to $37^{\circ} \mathrm{C}$ was injected into the lungs of the mice, and $1.0 \mathrm{ml}$ of each time was injected to fully fill the lungs. Bronchoalveolar lavage $1.0 \mathrm{ml} \times 10$ times was collected, and bronchoalveolar lavage fluid was collected. After centrifugation at $1500 \mathrm{r} / \mathrm{min}$ for $10 \mathrm{~min}$ at $4{ }^{\circ} \mathrm{C}$, the cells were washed once with PBS. Discard the supernatant, add DMEM medium containing $10 \%$ fetal bovine serum, and transfer to a cell culture flask. The cells were cultured in a $37^{\circ} \mathrm{C}, 5 \% \mathrm{CO}_{2}$ incubator for $4 \mathrm{~h}$, the supernatant and non-adherent cells were discarded, and the mouse alveolar macrophages were attached.

\subsection{Identification of mouse alveolar macrophages}

After the mice were killed, BALF was collected, centrifuged for $10 \mathrm{~min}$. We discarded the supernatant, added the post cell lysate, mixed it for $5 \mathrm{~min}$, lysed the red blood cells, centrifuged it again, then discarded the supernatant, and suspended the cells again with the cell culture solution. According to the characteristics of monocyte macrophages adhering to plastic or glass surface, but not lymph node cells, monocyte macrophages and lymphocytes were separated. The single cell suspension of culture medium 6 was placed in a culture plate with a cover 
glass, cultured in a $5 \% \mathrm{CO}_{2}$ cell incubator at $37^{\circ} \mathrm{C}$ for $4-6 \mathrm{~h}$, and then the culture medium was replaced. The adherent cells were macrophages. Then, Rieger Giemsa staining was used for identification. Take out the cell slide, dry it naturally, drop the dye fixative solution to cover the sample fully, fix it for $10 \mathrm{~min}$, suck and discard the fixative solution, wash it twice with PBS, drop the dye solution of Giemsa, dye it for $1.5 \mathrm{~min}$, drop the phosphate buffer solution of $\mathrm{pH} 6.4$ of the same amount, shake the slide gently, dye it for $4 \mathrm{~min}$, wash it with water, suck it dry, and perform microscopic examination. Under the microscope, the alveolar macrophages of mice were round, oval and fusiform in size. The nuclei were large and inclined to one side, stained dark blue, and the cytoplasm was gray blue.

\subsection{Cigarette Smoke Extract (CSE) preparation}

CSE was extracted from commercial Liqun cigarettes (11 mg Tar; $1.0 \mathrm{mg}$ nicotine; $11 \mathrm{mg}$ carbon monoxide; Xian Tobacco Company, Shannxi, China). Briefly, two cigarettes were combusted with a peristaltic pump without filter. Then smoke was passed through $10 \mathrm{ml}$ of serum-free RMPI-1640 medium using a vacuum pump. The $\mathrm{pH}$ of CSE was adjusted to 7.4 and the suspension was filtered through a $0.22 \mu \mathrm{m}$ pore-size filter to remove bacteria and large particles. Obtained solution was referred as 100\% CSE. Freshly solution would be prepared for each experiment. It was diluted with serum-free RMPI-1640 medium to the concentrations of $5 \%, 10 \%$, or $20 \%$ before the use.

\subsection{Cell lines and culture conditions}

Rat alveolar macrophage cell line NR8383 was purchased from American Type Culture Collection (ATCC, Manassas, VA, USA) and were maintained in Ham's F12-K medium supplemented with $10 \%$ fetal bovine serum (FBS, Gibco, Thermo Fisher Scientific, MA, USA), placed in a $37^{\circ} \mathrm{C}, 5 \% \mathrm{CO}_{2}$ cell culture incubator, and changed every $2 \mathrm{~d}$. For CSE exposure, NR8383 cells were seeded in 6-well plates at a density of $1 \times 10^{6}$ cells $/ \mathrm{ml}$, and cells were incubated with varied concentrations of CSE at 5\%, 10\%, or $20 \%$ for $24 \mathrm{~h}$, respectively.

\subsection{MicroRNA transfection}

MiR-155 mimic, NC-mimic, miR-155 inhibitor and NC-inhibitor were synthesized by GenePharama Company (Shanghai, China). The cells were transfected with these oligonucleotides by using Lipofectamine 2000 (Invitrogen, Carlsbad, CA, USA) according to the manufacturer's instruction. After transfection for $24 \mathrm{~h}$, cells were further cultured for $24 \mathrm{~h}$ and the incubated with $20 \%$ CSE for an additional $24 \mathrm{~h}$.

\subsection{Real-time quantitative PCR}

The total RNA from cells was extracted with the mir-Vana miRNA isolation kit (Ambion, USA) according to the manufacturer's protocol. qRT-PCR was performed on an ABI 7000 analyzer (Applied Biosystems, Foster City, CA, USA) by using the SYBR Green PCR Master Mix (Applied Biosystems). Expression data were uniformly normalized to U6, serving as the internal control. Relative gene expression was quantified by using the 2- $\Delta \Delta \mathrm{Ct}$ method.

\subsection{ELISA analysis}

Cytokine concentrations from the supernatants of NR8383 cells after appropriate treatment were determined by using tumor necrosis factor- $\alpha$ (TNF- $\alpha$ ), interleukins (IL)-6, interleukins (IL)-8 ELISA kits (R\&D Systems, Minneapolis, USA) according to the manufacturer's instructions.

\subsection{Western blot assay}

Proteins from cells were lysed in MCLB, and the total protein concentration was determined using BCA assay (Aspen, Wuhan, China). Equal amounts of sample proteins were resolved by SDS-PAGE gel and transferred to poly-vinylidene difluoride membranes (Millipore, Billerica, MA, USA).

After blocking, membranes were incubated with primary antibodies including anti-Beclin1 (Cell Signaling Technologies, MA, USA), anti-LC3II (Cell Signaling Technologies, MA, USA), anti-p62 (Cell Signaling Technologies, MA, USA), GAPDH (Abcam, Cambridge, MA, USA) at $4{ }^{\circ} \mathrm{C}$ overnight. After rinsing, the membranes were incubated with Goat anti-rabbit or mouse horseradish peroxidase (HRP)-conjugated secondary antibodies (Abcam, Cambridge, MA, USA) at $37^{\circ} \mathrm{C}$ for $1 \mathrm{~h}$. The bands were detected by ECL detection reagents (Beyotime Biotechnology, Shanghai, China), and GAPDH was used as an internal control.

\subsection{Statistical analysis}

Data were expressed as mean \pm standard deviation (SD) by using the GraphPad Prism 6.0 software (Prism, San Diego, CA, USA). Differences between groups were examined using Student's unpaired $t$ test and comparisons among multiple groups were analyzed by using one-way ANOVA. A P value $<0.05$ was considered as statistically significant.

\section{Results}

\subsection{MiR-155 was up-regulated in COPD bronchoalveoar lavage fluid and CSE-mediated NR8383 cell line}

To assess the effect of miR-155 on CSE exposure in vivo and in vitro, we assessed the expression of miR-155 in alveolar macrophages of COPD patients, dynamic COPD mouse model and alveolar macrophages cell lines NR8383 cell line by qRT-PCR. Compared with specimens from non-smoker group, the expression level of miR-145-5p was remarkably upregulated in lung tissues of smokers with COPD $(p<0.01$, respectively, Figure 1A). Furthermore, the expression of miR-155 was gradually increased with the severity of COPD. Meanwhile, the expression of miR-155 was remarkably upregulated in alveolar macrophages of COPD dynamic mouse model with the severity of COPD $(p<0.01$, Figure 1B). The qRT-PCR showed that CSE could concentration-dependently promote the expression of miR-155 ( $p<0.05$, Figure 1C). Thus, these findings indicated that upregulation of miR-145-5p might be associated with the pathogenesis of COPD. 

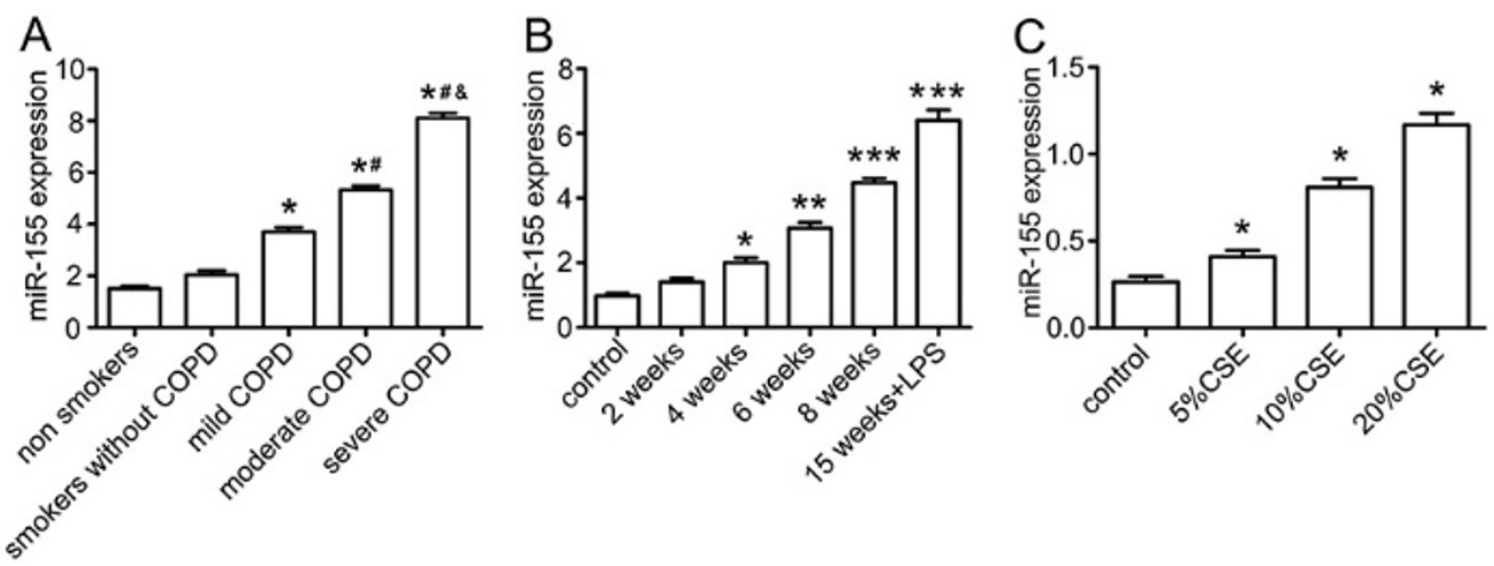

Figure 1. The expression of miR-155 in patients, COPD dynamic mouse model and NR8383 cells. (A) The expression of miR-155 in alveolar macrophages of healthy control, smoker (without COPD) and varying degrees of severity of COPD patients; Mean $\pm \mathrm{SD} ; \mathrm{n}=10,{ }^{*} p<0.05$ vs healthy control group; ${ }^{*} p<0.05$ vs mild COPD group; ${ }^{\circledR} p<0.05$ vs moderate COPD group; (B) The expression of miR- 155 in alveolar macrophages of COPD dynamic mouse model; Mean \pm SD; $\mathrm{n}=8$; ${ }^{\star} p<0.05 ;{ }^{\star *} p<0.01$; ${ }^{\star *} p<0.001$ vs control group; (C) The expression of miR-155 in NR8383 cells; ${ }^{*} p<0.05$ vs control group.

A

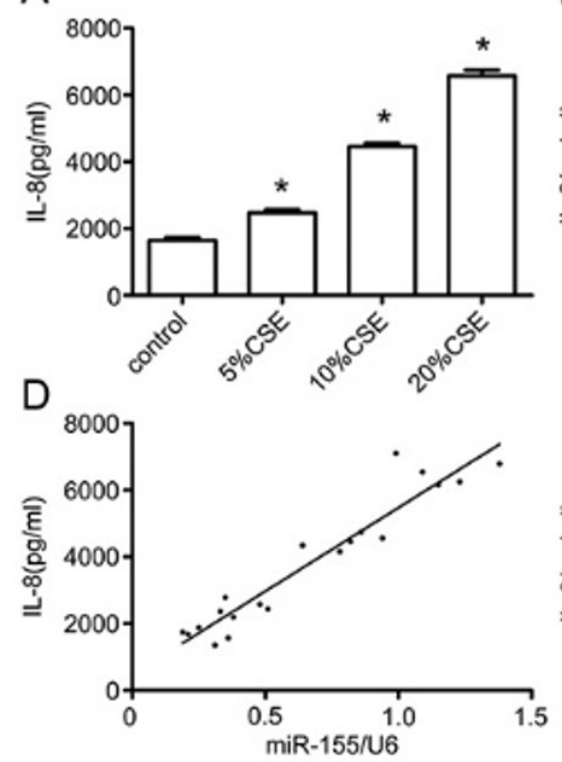

B

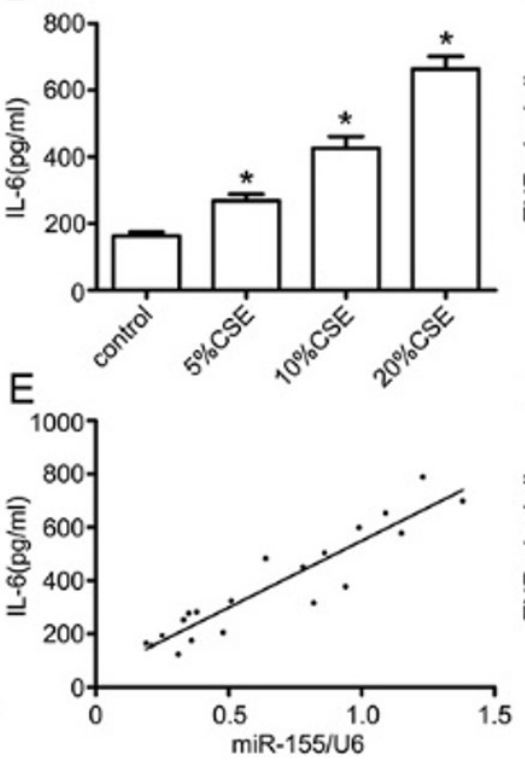

C
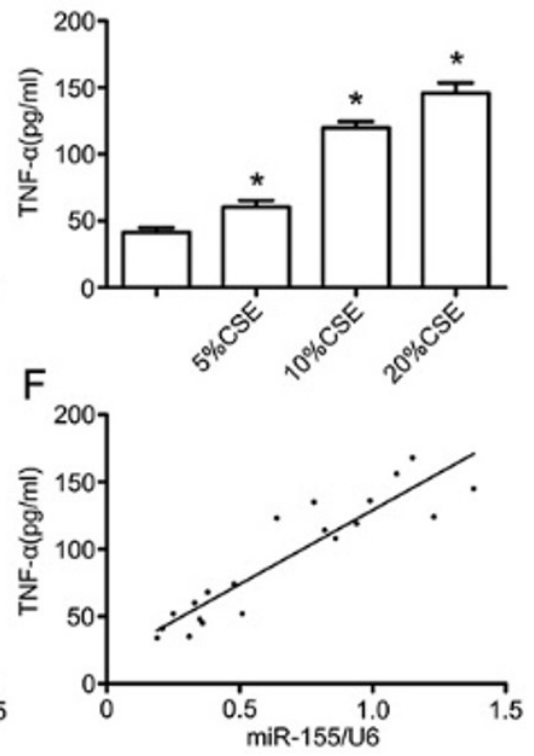

Figure 2. The levels of miR-155 was correlated with CSE-induced inflammation response in NR8383 cells; (A) The levels of IL-8; (B) The levels of TNF- $\alpha$; (C) The levels of IL-6; (D) miR-155 was correlated with IL-8; (E) MiR-155 was correlated with IL-6; (F) MiR-155 was correlated with TNF- $\alpha$; Mean \pm SD; $\mathrm{n}=5 ;{ }^{*} p<0.05$ vs control group.

\subsection{MiR-155 is involved in the regulation of CSE-induced NR8383 cells inflammatory response}

To investigate the effect of miR- 155 on CSE-mediated COPD NR8383 cell inflammatory response, in vitro NR8383 cells with (5\%, $10 \%$ and $20 \%$ ) CSE exposure was performed. The proinflammatory factors in cell culture were detected by ELISA. It was found that CSE could concentration-dependently promote the production of IL-8, TNF- $\alpha$ and IL-6 in NR8383 cells $(p<0.05$, Figure 2A, B, C). Spearman correlation analysis showed that the expression level of miR-155 was positively correlated with the levels of pro-inflammatory cytokines IL-8, IL- 6 and TNF- $\alpha$ $(p<0.05$, Figure 2D-F). The qRT-PCR was used to confirm that under CSE condition, miR-155 inhibitor (miR-155 I) inhibited the expression of mir-155, while miR-155 mimic (miR-155 m) increased the expression of miR-155 ( $p<0.05$, Figure $3 \mathrm{~A})$. ELISA results showed that miR-155 inhibitor could partially reverse the production of TNF- $\alpha$, IL- 6 and IL- 8 in NR8383 cells $(p<0.05$, Figure 3B-D). Moreover, miR-155 mimic showed synergistic effects with CSE, which could further promote the production of TNF- $\alpha$, IL- 6 and IL-8 in NR8383 cells induced by CSE $(p<0.05$, Figure 3B-D). These results suggested that 
A
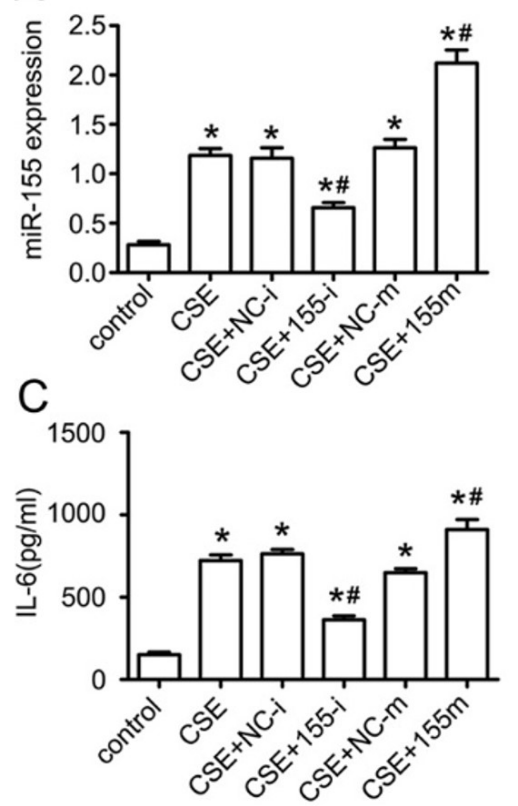

B
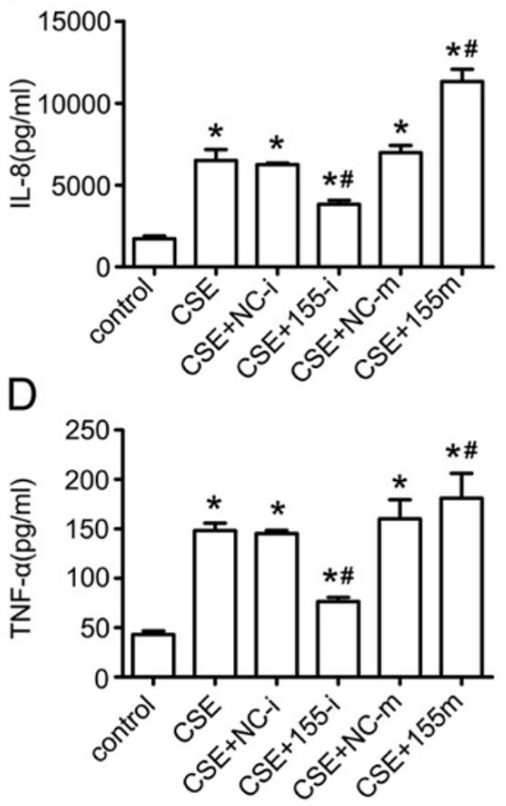

Figure 3. MiR-155 was involved in the regulation of CSE-induced inflammation responses in the NR8383 cells; (A) The efficiency of miR-155 mimic and miR-155 inhibitor transfection was evaluated by RT-qPCR; (B) The levels of IL-8; (C) The levels of IL-6; (D) The levels of TNF- $\alpha$; Mean $\pm \mathrm{SD} ; \mathrm{n}=3 ;{ }^{*} p<0.05$ vs control group; ${ }^{*} p<0.05$ vs CSE group.
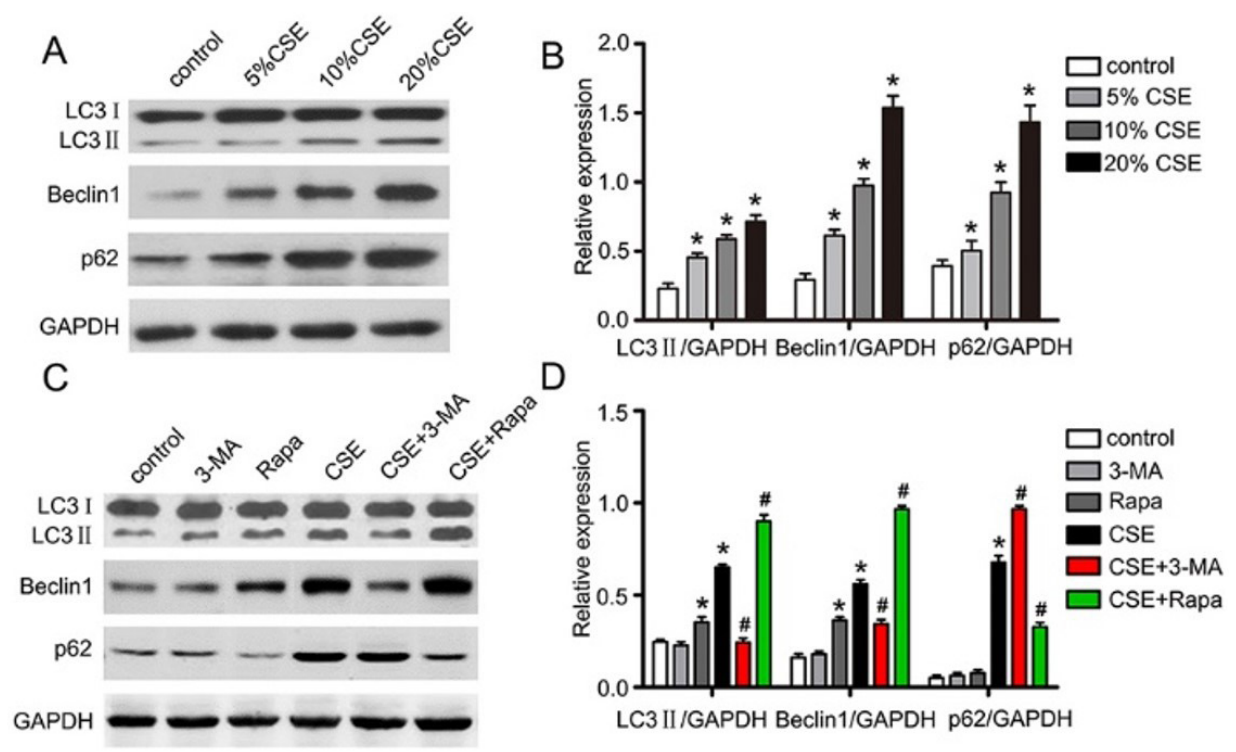

Figure 4. CSE could concentration-dependently promote the expression of Beclin1, LC3II and p62 expression; (A), (B) CSE induced autophagy disorder in NR8383 cells; Mean \pm SD; $\mathrm{n}=3$; ${ }^{*} p<0.05$ vs control group; (C), (D) The expressions of LC3II, Beclin1 and p62; Mean \pm SD; $\mathrm{n}=3$; ${ }^{*} p<0.05$ vs control group; ${ }^{*} p<0.05$ vs CSE group.

miR-155 might be involved in the CSE-induced inflammatory response of NR8383 cells.

\subsection{The introduction of autophagy could inhibit CSE-induced NR8383 cell inflammatory response.}

CSE could concentration-dependently promote the expression of Beclin1, LC3II and p62 ( $p<0.05$, Figure 4A, B). It suggested that CSE induced autophagy disorder in NR8383 cells.
Moreover, without CSE stimulation, 3-MA had no effect on the expression of LC3 II, Beclin1, p62 ( $p>0.05$, Figure 4C, D). Rapa could increase the expression of LC3 II, Beclin1, but had no effect on the expression of p62 $(p>0.05$, Figure 4 C, D). Under CSE stimulation, 3-MA could suppress the expression of LC3 and Beclin $1(p<0.05$, Figure 4 C, D), promote the expression of p62 ( $p<0.05$, Figure 4 C, D). Meanwhile, Rapa could promote the expression of LC3 and Beclin 1 and inhibit the expression of p62 $(p<0.05$, Figure $4 \mathrm{C}, \mathrm{D})$. 
ELISA results showed that 3-MA could further promote the production of TNF- $\alpha$, IL-6 and IL-8 in NR8383 cells $(p<0.05$, Figure 5A-C), which had a synergistic effect with CSE. Rapa could partially reverse the production of TNF- $\alpha$, IL- 6 and IL-8 in NR8383 cells induced by CSE ( $p<0.05$, Figure 5A-C). However, 3-MA or Rapa had no effect on the expression of miR-155 (Figure 5D).

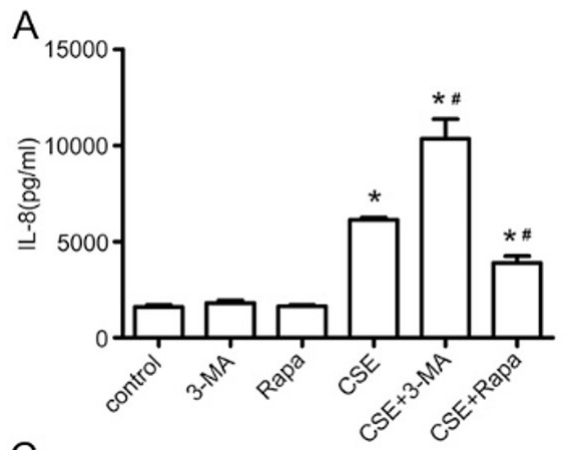

C

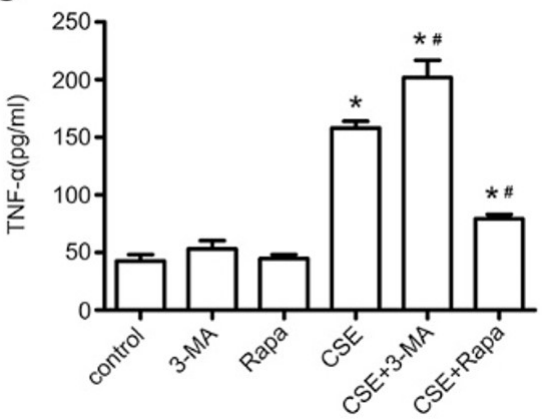

\subsection{MiR-155 is involved in the regulation of CSE-induced autophagy disorder in NR8383 cells}

MiR-155 mimic could promote the expression of LC3II, Beclin 1 and p62 under CSE stimulation ( $<<0.05$, Figure $6 A, B)$, suggesting that miR-155 mimic aggravated the autophagy disorder of NR8383 cells. Furthermore, miR-155 inhibitor could inhibit the expression of LC3II, Beclin 1 and p62 $(p<0.05$, Figure 6C, D),
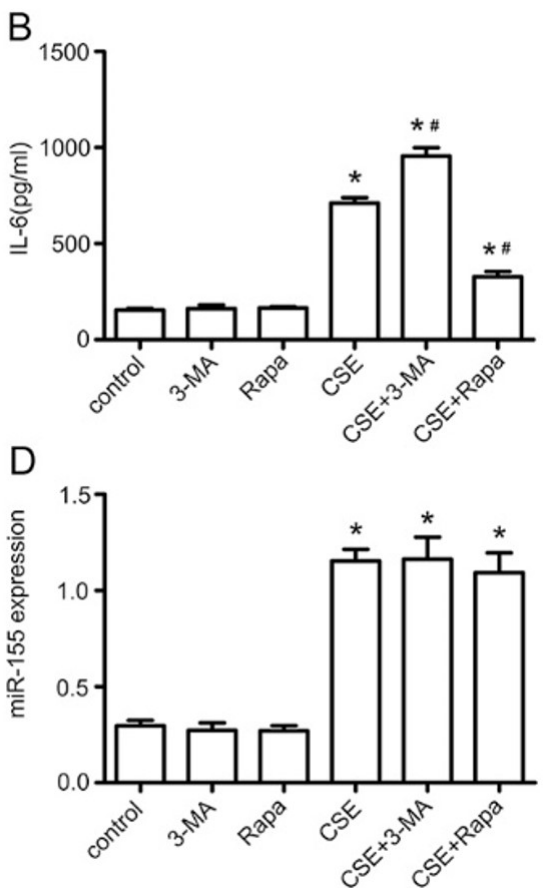

Figure 5. The effect of autophagy on the levels of miR-155 and CSE-induced productions of proinflammatory factors in the NR8383 cells; (A) The levels of TNF- $\alpha$; (B) The levels of IL-6; (C) The levels of IL-8; (D) The levels of miR-155; Mean \pm SD; $n=3$; ${ }^{*} p<0.05$ vs control group; ${ }^{*} p<0.05$ vs CSE group.
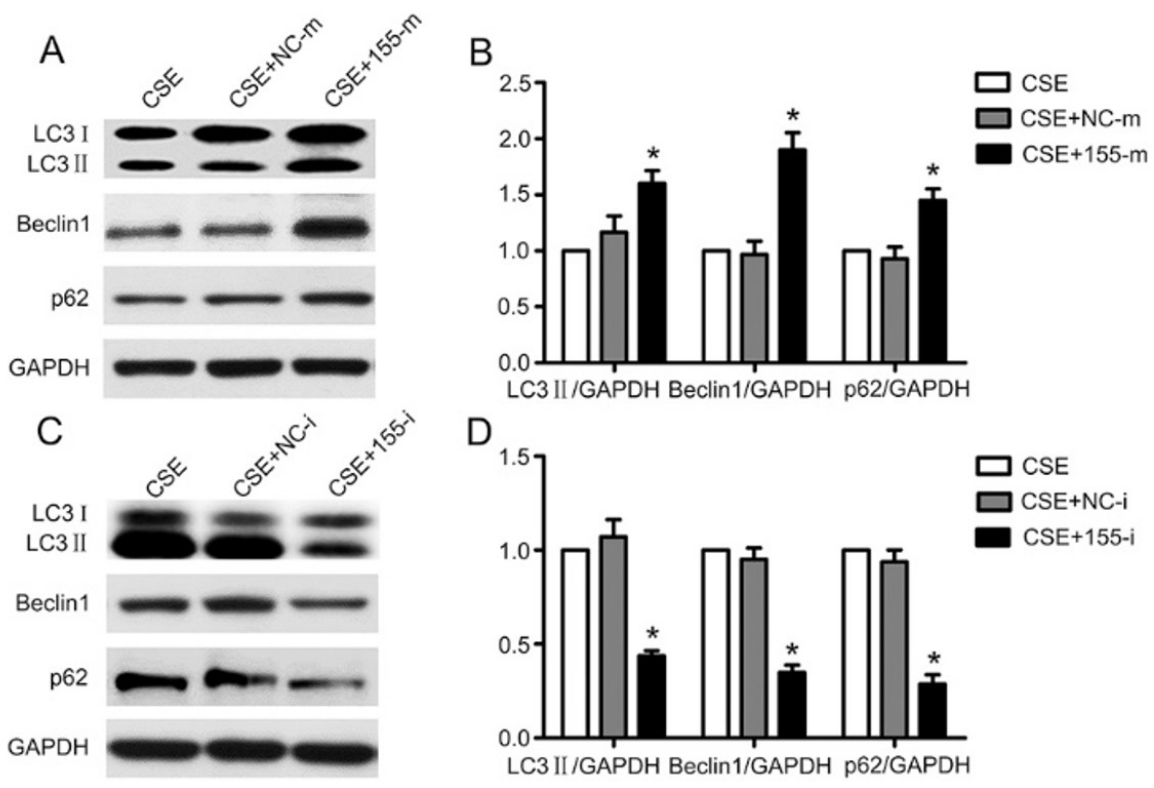

D

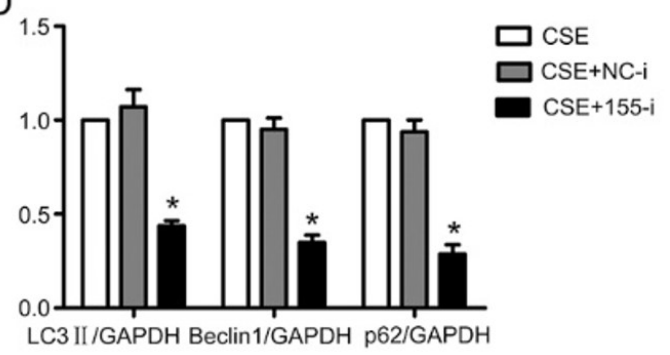

Figure 6. MiR-155 was involved in the regulation of CSE-induced autophagic dysfunction in NR8383 cells; (A), (B) The effect of miR-155 mimic on CSE-induced protein expression of LC3II, Beclin1 and p62; (C), (D) The effect of miR-155 inhibitor on CSE-induced protein expression of LC3II, Beclin1 and p62; Mean $\pm \mathrm{SD} ; \mathrm{n}=3 ;{ }^{*} p<0.05$ vs control group. 

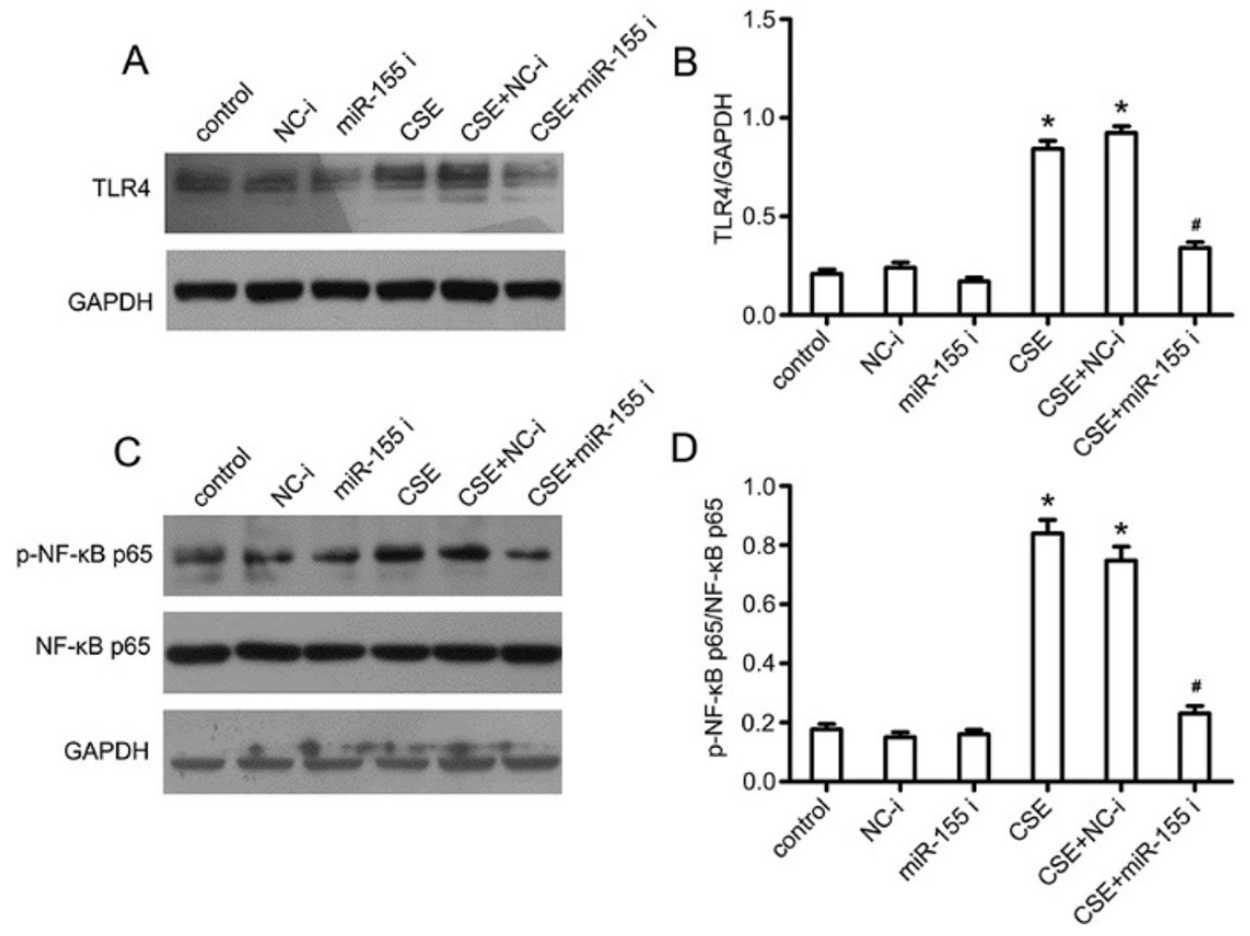

Figure 7. MiR-155 inhibited TLR4/NF- $\kappa B$ signal pathway in NR8383 cells under CSE stimulation; (A), (B) MiR-155 inhibitor inhibited TLR4 expression under CSE stimulation; (C), (D) MiR-155 inhibitor inhibited p-NF- $\kappa$ B p65 expression under CSE stimulation; Mean \pm SD; $\mathrm{n}=3 ;{ }^{\star} p$ $<0.05$ vs control group.

suggesting that miR-155 inhibitor inhibited CSE-induced autophagy disorder in NR8383 cells.

\subsection{MiR-155 inhibited TLR4/NF-kB singnal pathway in NR8383 cells under CSE condition.}

The expression of TLR4 and NF- $\mathrm{kB}$ in NR8383 cells with CSE treatment was increased compared with NR8383 cells without CSE stimulation $(p<0.05$, Figure 7A-D), moreover, the increased expression of TLR4 and NF- $\mathrm{KB}$ in NR8383 cells with CSE stimulation was greatly decreased in miR- 155 i group $(p<0.05$, Figure 7A-D). It suggested that the TLR4/NF- $\kappa B$ signal pathway might be the keyway, by which miR-155 regulated the autophagy and inflammation in CSE-treated NR8383 cells.

\section{Discussion}

In current study, we investigated that the potential role of miR-155 in the progression of COPD. Our results showed that miR-155 was upregulated in the alveolar macrophages from bronchoalveolar lavage fluid of COPD patients, COPD dynamic mouse model and CSE-treated NR8383 cell line. Overexpression of miR-155 led to dysregulation of cell autophagy and was closely related to the expression of proinflammatory cytokine TNF- $\alpha$, IL-6, IL-8 in NR8383 cell line, while inhibition of miR-155 significantly reversed CSE induced cell autophagy dysregulation and inflammation in NR8383 cell line. In addition, we found that miR-155 promoted cell autophagy by directly targeting TLR4/NF- $\kappa B$ pathway in NR8383 cell line.
The pathogenesis of COPD is complicated, it is mainly considered that the particulate solid phase and toxic gases in the air stimulate the lung tissue, induce chronic airway inflammation, and eventually lead to pulmonary dysfunction (Tuder \& Petrache, 2012). Alveolar macrophages play an important role in the inflammatory response and the pathophysiology of COPD (Barnes, 2004). Accordingly, alveolar macrophage cell line (NR8383) was performed in this study to investigate the correlation between CSE exposure and the pathological processes of COPD associated with miR-155 expression.

Emerging evidence has revealed that miRNAs were involved in COPD physiological and pathological processes, and miRNAs might be involved in the regulation of inflammation in the lung. A previous study has suggested that the miR-155 was upregulated in cigarettes induced COPD mouse model and lung tissues of COPD patients compared with the non-smoker controls (Conickx et al., 2017). In the present study, we found that the miR-155 level was increased in alveolar macrophages of COPD patients and COPD dynamic mouse model, and miR-155 expression gradually increases with the severity of COPD, and also increased in a concentration dependent manner in NR8383 cells line with CSE treatment. Moreover, we showed that IL-6, IL-8 and TNF- $\alpha$ were increased in a concentration dependent manner in NR8383 cells line with CSE treatment, and the expression level of miR-155 was positively correlated with the levels of pro-inflammatory factors IL-8, IL-6 and TNF- $\alpha$. In addition, we also found that miR-155 inhibitor partially reversed the production of TNF- $\alpha$, IL- 6 and IL- 8 in 
NR8383 cells, while miR-155 mimic could further promote the production of TNF- $\alpha$, IL- 6 and IL- 8 in NR8383 cells induced by CSE. These results imply that miR-155 might be involved in the airway inflammation in COPD.

Previous studies have shown that the expression of autophagy protein was increased in the lung of COPD patients (Chen et al., 2008; Ryter et al., 2010). In lung tissues obtained from COPD patients, it was observed that autophagic proteins LC3B, Atg4, Atg5/12 and Atg7 were enhanced in lung epithelial cells, while histone deacetylase (HDAC) activity was decreased, resulting in an increase in autophagy level (Chen et al., 2008). Daniel et al. found a correlation between the level of circulating Beclin 1 and the degree of airflow obstruction, which was consistent with a progressive defect in autophagy during COPD (Schlemmer et al., 2018). Schlemmer et al. (2018) identified that both autophagosomes and p62 were accumulated in smokers' alveolar macrophages (Monick et al., 2010). Autophagy was a homeostatic process involved in the degradation of proteins or organelles, it played critical roles in regulation of the development and survival of inflammatory cells (Racanelli et al., 2018). Consistent with our study, we found that the Beclin1, LC3II and p62 expressions were increased in CSE treatment NR8383 cells compared with the control groups. In addition, we also found that autophagy inhibitor 3-MA promote the production of TNF- $\alpha$, IL- 6 and IL-8 in NR8383 cells, while Autophagy agonist Rapa could partially reverse the production of TNF- $\alpha$, IL- 6 and IL- 8 induced by CSE in NR8383 cells. These results imply that autophagy might be involved in the airway inflammation in COPD.

Most previous studies have showed that a dysregulated autophagic process in the lung of COPD patients, leading to cellular senescence and accumulation of damaged protein aggregates (Fujii et al., 2012; Lam et al., 2013; Even et al., 2018). Our results showed that CSE concentration-dependently promoted the expression of Beclin1, LC3II and p62 expression. The results suggested that CSE induced autophagy disorder in NR8383 cells. In addition, we found that miR-155 mimic promoted the expression of LC3II, Beclin1 and p62, suggesting that miR-155 mimic aggravated the autophagy disorder in CSE-induced NR8383 cells, while miR-155 inhibitor could inhibit the expression of LC3II, Beclin1 and p62, suggesting that miR-155 inhibitor inhibits autophagy disorder in CSE-induced NR8383 cells. This finding implied that miR- 155 contributed to autophagy dysregulation of NR8383 cells induced by CSE, promoted the secretion of a large number of inflammatory factors, which eventually led to COPD inflammatory reaction.

TLR4/NF- $k B$ signal pathway is a key regulator in which autophagy is involved in the regulation of COPD inflammatory responses. In alveolar macrophages of COPD patients, autophagy is disrupted, disrupting intracellular homeostasis, activating Toll-like Receptor 4 (TLR4), and pathogen-associated Molecular Pattern (PAMP) After binding, the nuclear factor kappa B (nuclear factor- $\mathrm{\kappa B}, \mathrm{NF}-\kappa \mathrm{B}$ )-related signaling pathway induces the activation of various pro-inflammatory factor genes and promotes the secretion of inflammatory factors (Brusselle et al., 2011). TLR4 is a pattern recognition receptor that responds to LPS, which plays a crucial role in the inflammatory response. The binding of LPS to TLR4 employs IRAK-1 and TRAF6 to induce inflammatory signaling for the activation of NF- $\mathrm{kB}$, while miR-155 are immunomodulatory microRNAs that play crucial roles in suppressing NF- $\kappa B$ signaling pathway at different stages. We also show that TLR 4 and NF- $\kappa B$ expression is increased in CSE-induced NR8383 cells. Moreover, miR-155 inhibitor inhibited the TLR4 and NF- $\mathrm{KB}$ expression in NR8383 cells under CSE condition. These results imply that miR-155 may contribute to the airway inflammation in COPD by regulating autophagy in alveolar macrophages cells via targeting TLR4/NF- $\mathrm{KB}$ pathway.

In conclusion, this study revealed a novel inflammatory role of miR-155 in COPD and the related mechanisms. We provide a new perspective to understand the pathogenesis of COPD, and miR-155 might be useful as potential target for the treatment of COPD.

\section{Abbreviations}

COPD: Chronic obstructive pulmonary disease. CSE: cigarette smoke extract. COLD: Chronic Obstruct Lung Disease. TNF- $\alpha$ : tumor necrosis factor- $\alpha$. IL: interleukins. HRP: horseradish peroxidase. SD: standard deviation.

\section{Ethical approval}

The study was approved by the medical ethics committee of Union Hospital, Tongji Medical College, Huazhong University of Science and Technology. All patients agreed to participate in the study and signed the informed consent form.

\section{Conflict of interest}

There are no potential conflicts of interest to disclose.

\section{Author Contributions}

Mingliang Wang is resposible for the study design, literature research, experimental studies, data analysis, manuscript preparation \& editing. Wendong Wang is resposible for the clinical studies. Jiashun Wang is resposible for the data acquisition. Jun Zhang is resposible for the guarantor of integrity of the entire study, study concepts \& design, literature research, statistical analysis, manuscript editing \& review. All authors read and approved the final manuscript.

\section{References}

Barnes, P. J. (2004). Alveolar macrophages as orchestrators of COPD. COPD: Journal of Chronic Obstructive Pulmonary Disease, 1(1), 5970. http://dx.doi.org/10.1081/COPD-120028701. PMid:16997739.

Brusselle, G. G., Joos, G. F., \& Bracke, K. R. (2011). New insights into the immunology of chronic obstructive pulmonary disease. The Lancet, 378(9795), 1015-1026. http://dx.doi.org/10.1016/S01406736(11)60988-4. PMid:21907865.

Chen, Z. H., Kim, H. P., Sciurba, F. C., Lee, S. J., Feghali-Bostwick, C., Stolz, D. B., Dhir, R., Landreneau, R. J., Schuchert, M. J., Yousem, S. A., Nakahira, K., Pilewski, J. M., Lee, J. S., Zhang, Y., Ryter, S. W., \& Choi, A. M. (2008). Egr-1 regulates autophagy in cigarette smoke-induced chronic obstructive pulmonary disease. PLoS One, 3(10), e3316. http://dx.doi.org/10.1371/journal.pone.0003316. PMid:18830406. 
Cheng, W. T., Guo, Z. X., Lin, C. A., Lin, M. Y., Tung, L. C., \& Fang, K. (2009). Oxidative stress promotes autophagic cell death in human neuroblastoma cells with ectopic transfer of mitochondrial PPP2R2B (Bbeta2). BMC Cell Biology, 10(1), 91. http://dx.doi.org/10.1186/14712121-10-91. PMid:20017961.

Conickx, G., Avila Cobos, F., van den Berge, M., Faiz, A., Timens, W., Hiemstra, P. S., Joos, G. F., Brusselle, G. G., Mestdagh, P., \& Bracke, K. R. (2017). microRNA profiling in lung tissue and bronchoalveolar lavage of cigarette smoke-exposed mice and in COPD patients: a translational approach. Scientific Reports, 7(1), 12871. http://dx.doi. org/10.1038/s41598-017-13265-8. PMid:28993685.

Even, B., Fayad-Kobeissi, S., Gagliolo, J. M., Motterlini, R., Boczkowski, J., Foresti, R., \& Dagouassat, M. (2018). Heme oxygenase-1 induction attenuates senescence in chronic obstructive pulmonary disease lung fibroblasts by protecting against mitochondria dysfunction. Aging Cell, 17(6), e12837. http://dx.doi.org/10.1111/acel.12837. PMid:30341816.

Faraoni, I., Antonetti, F. R., Cardone, J., \& Bonmassar, E. (2009). MiR-155 gene: a typical multifunctional microRNA. Biochimica et Biophysica Acta, 1792(6), 497-505. http://dx.doi.org/10.1016/j. bbadis.2009.02.013. PMid:19268705.

Fujii, S., Hara, H., Araya, J., Takasaka, N., Kojima, J., Ito, S., Minagawa, S., Yumino, Y., Ishikawa, T., Numata, T., Kawaishi, M., Hirano, J., Odaka, M., Morikawa, T., Nishimura, S., Nakayama, K., \& Kuwano, K. (2012). Insufficient autophagy promotes bronchial epithelial cell senescence in chronic obstructive pulmonary disease. OncoImmunology, 1(5), 630-641. http://dx.doi.org/10.4161/onci.20297. PMid:22934255.

Ha, J., \& Kim, J. (2016). Novel pharmacological modulators of autophagy: an updated patent review (2012-2015). Expert Opinion on Therapeutic Patents, 26(11), 1273-1289. http://dx.doi.org/10.1080/13543776.20 16.1217996. PMid:27476990.

Heckmann, B. L., Boada-Romero, E., Cunha, L. D., Magne, J., \& Green, D. R. (2017). LC3-Associated Phagocytosis and Inflammation. Journal of Molecular Biology, 429(23), 3561-3576. http://dx.doi. org/10.1016/j.jmb.2017.08.012. PMid:28847720.

Katsuragi, Y., Ichimura, Y., \& Komatsu, M. (2015). p62/SQSTM1 functions as a signaling hub and an autophagy adaptor. The FEBS Journal, 282(24), 4672-4678. http://dx.doi.org/10.1111/febs.13540. PMid:26432171.

Kim, K. H., Kang, H. S., Kim, J. S., Yoon, H. K., Kim, S. K., \& Rhee, C. K. (2017). Risk factors for the discontinuation of roflumilast in patients with chronic obstructive pulmonary disease. International Journal of Chronic Obstructive Pulmonary Disease, 12, 3449-3456. http://dx.doi.org/10.2147/COPD.S143967. PMid:29270006.

Lam, H. C., Cloonan, S. M., Bhashyam, A. R., Haspel, J. A., Singh, A., Sathirapongsasuti, J. F., Cervo, M., Yao, H., Chung, A. L., Mizumura, K., An, C. H., Shan, B., Franks, J. M., Haley, K. J., Owen, C. A., Tesfaigzi, Y., Washko, G. R., Quackenbush, J., Silverman, E. K., Rahman, I., Kim, H. P., Mahmood, A., Biswal, S. S., Ryter, S. W., \& Choi, A. M. (2013). Histone deacetylase 6-mediated selective autophagy regulates COPD-associated cilia dysfunction. The Journal of Clinical Investigation, 123(12), 5212-5230. http://dx.doi. org/10.1172/JCI69636. PMid:24200693.

Li, Z., \& Rana, T. M. (2014). Therapeutic targeting of microRNAs: current status and future challenges. Nature Reviews. Drug Discovery, 13(8), 622-638. http://dx.doi.org/10.1038/nrd4359. PMid:25011539.

Mayer, A. S., \& Newman, L. S. (2001). Genetic and environmental modulation of chronic obstructive pulmonary disease. Respiration
Physiology, 128(1), 3-11. http://dx.doi.org/10.1016/S00345687(01)00258-4. PMid:11535256.

Monick, M. M., Powers, L. S., Walters, K., Lovan, N., Zhang, M., Gerke, A., Hansdottir, S., \& Hunninghake, G. W. (2010). Identification of an autophagy defect in smokers' alveolar macrophages. Journal of Immunology, 185(9), 5425-5435. http://dx.doi.org/10.4049/ jimmunol.1001603. PMid:20921532.

Murugan, V., \& Peck, M. J. (2009). Signal transduction pathways linking the activation of alveolar macrophages with the recruitment of neutrophils to lungs in chronic obstructive pulmonary disease. Experimental Lung Research, 35(6), 439-485. http://dx.doi. org/10.1080/01902140902759290. PMid:19842832.

Parzych, K. R., \& Klionsky, D. J. (2014). An overview of autophagy: morphology, mechanism, and regulation. Antioxidants \& Redox Signalling, 20(3), 460-473. http://dx.doi.org/10.1089/ars.2013.5371. PMid:23725295.

Pociask, D. A., Robinson, K. M., Chen, K., McHugh, K. J., Clay, M. E., Huang, G. T., Benos, P. V., Janssen-Heininger, Y. M. W., Kolls, J. K., Anathy, V., \& Alcorn, J. F. (2017). Epigenetic and transcriptomic regulation of lung repair during recovery from influenza infection. The American Journal of Pathology, 187(4), 851-863. http://dx.doi. org/10.1016/j.ajpath.2016.12.012. PMid:28193481.

Postma, D. S., Bush, A., \& Berge, M. (2015). Risk factors and early origins of chronic obstructive pulmonary disease. The Lancet, 385(9971), 899-909. http://dx.doi.org/10.1016/S0140-6736(14)604463. PMid:25123778.

Proboszcz, M., Paplinska-Goryca, M., Nejman-Gryz, P., Gorska, K., \& Krenke, R. (2017). A comparative study of sTREM-1, IL-6 and IL-13 concentration in bronchoalveolar lavage fluid in asthma and COPD: a preliminary study. Advances in Clinical and Experimental Medicine, 26(2), 231-236. http://dx.doi.org/10.17219/acem/64875. PMid:28791839.

Racanelli, A. C., Kikkers, S. A., Choi, A. M. K., \& Cloonan, S. M. (2018). Autophagy and inflammation in chronic respiratory disease. Autophagy, 14(2), 221-232. http://dx.doi.org/10.1080/15548627.20 17.1389823. PMid:29130366.

Ryter, S. W., \& Choi, A. M. (2010). Autophagy in the lung. Proceedings of the American Thoracic Society, 7(1), 13-21. http://dx.doi.org/10.1513/ pats.200909-101JS. PMid:20160144.

Ryter, S. W., Lee, S. J., \& Choi, A. M. (2010). Autophagy in cigarette smoke-induced chronic obstructive pulmonary disease. Expert Review of Respiratory Medicine, 4(5), 573-584. http://dx.doi.org/10.1586/ ers.10.61. PMid:20923337.

Schlemmer, F., Boyer, L., Soumagne, T., Ridoux, A., Chouaid, C., Maitre, B., Lanone, S., Adnot, S., Audureau, E., \& Boczkowski, J. (2018). Beclin1 circulating levels and accelerated aging markers in COPD. Cell Death \& Disease, 9(2), 156. http://dx.doi.org/10.1038/ s41419-017-0178-1. PMid:29402890.

Sukkar, M. B., \& Harris, J. (2017). Potential impact of oxidative stress induced growth inhibitor 1 (OSGIN1) on airway epithelial cell autophagy in chronic obstructive pulmonary disease (COPD). Journal of Thoracic Disease, 9(12), 4825-4827. http://dx.doi.org/10.21037/ jtd.2017.10.153. PMid:29312667.

Thepen, T., Kraal, G., \& Holt, P. G. (1994). The role of alveolar macrophages in regulation of lung inflammation. Annals of the New York Academy of Sciences, 725(1), 200-206. http://dx.doi. org/10.1111/j.1749-6632.1994.tb39802.x. PMid:8030991. 
Tuder, R. M., \& Petrache, I. (2012). Pathogenesis of chronic obstructive pulmonary disease. The Journal of Clinical Investigation, 122(8), 2749-2755. http://dx.doi.org/10.1172/JCI60324. PMid:22850885.

Wu, Y. F., Li, Z. Y., Dong, L. L., Li, W. J., Wu, Y. P., Wang, J., Chen, H. P., Liu, H. W., Li, M., Jin, C. L., Huang, H. Q., Ying, S. M., Li, W., Shen, H. H., \& Chen, Z. H. (2020). Inactivation of MTOR promotes autophagy-mediated epithelial injury in particulate matter-induced airway inflammation. Autophagy, 16(3), 435-450. http://dx.doi.org /10.1080/15548627.2019.1628536. PMid:31203721.
Zech, A., Ayata, C. K., Pankratz, F., Meyer, A., Baudiß, K., Cicko, S., Yegutkin, G. G., Grundmann, S., \& Idzko, M. (2015). MicroRNA-155 modulates $\mathrm{P} 2 \mathrm{R}$ signaling and Th2 priming of dendritic cells during allergic airway inflammation in mice. Allergy, 70(9), 1121-1129. http://dx.doi.org/10.1111/all.12643. PMid:25944053.

Zeng, Z., He, S., Lu, J., Liu, C., Lin, H., Xu, C., Xie, L., \& Sun, S. (2018). MicroRNA-21 aggravates chronic obstructive pulmonary disease by promoting autophagy. Experimental Lung Research, 44(2), 89-97. http://dx.doi.org/10.1080/01902148.2018.1439548. PMid:29543496. 